OPEN ACCESS

Edited by:

Ildikò Szabò,

University of Padova, Italy

Reviewed by:

Ingo Dreyer,

Universidad de Talca, Chile

Katrin Philippar,

Ludwig-Maximilians-University

Munich, Germany

*Correspondence:

Igor Pottosin

pottosin@ucol.mx

Specialty section:

This article was submitted to

Plant Physiology,

a section of the journal

Frontiers in Physiology

Received: 30 September 2015 Accepted: 04 December 2015 Published: 22 December 2015

Citation:

Pottosin I and Dobrovinskaya O (2015)

Ion Channels in Native Chloroplast

Membranes: Challenges and Potential for Direct Patch-Clamp Studies.

Front. Physiol. 6:396.

doi: 10.3389/fphys.2015.00396

\section{Ion Channels in Native Chloroplast Membranes: Challenges and Potential for Direct Patch-Clamp Studies}

\author{
Igor Pottosin * and Oxana Dobrovinskaya \\ Centro Universitario de Investigaciones Biomédicas, Universidad de Colima, Colima, Mexico
}

Photosynthesis without any doubt depends on the activity of the chloroplast ion channels. The thylakoid ion channels participate in the fine partitioning of the light-generated proton-motive force (p.m.f.). By regulating, therefore, luminal $\mathrm{pH}$, they affect the linear electron flow and non-photochemical quenching. Stromal ion homeostasis and signaling, on the other hand, depend on the activity of both thylakoid and envelope ion channels. Experimentally, intact chloroplasts and swollen thylakoids were proven to be suitable for direct measurements of the ion channels activity via conventional patch-clamp technique; yet, such studies became infrequent, although their potential is far from being exhausted. In this paper we wish to summarize existing challenges for direct patch-clamping of native chloroplast membranes as well as present available results on the activity of thylakoid $\mathrm{Cl}^{-}(\mathrm{ClC}$ ?) and divalent cation-permeable channels, along with their tentative roles in the p.m.f. partitioning, volume regulation, and stromal $\mathrm{Ca}^{2+}$ and $\mathrm{Mg}^{2+}$ dynamics. Patch-clamping of the intact envelope revealed both large-conductance porin-like channels, likely located in the outer envelope membrane and smaller conductance channels, more compatible with the inner envelope location. Possible equivalent model for the sandwich-like arrangement of the two envelope membranes within the patch electrode will be discussed, along with peculiar properties of the fast-activated cation channel in the context of the stromal $\mathrm{pH}$ control.

Keywords: chloroplast envelope, cation channel, CIC channel, magnesium, patch-clamp, porin, proton-motive force, thylakoid

\section{INTRODUCTION}

Chloroplasts originated from endosymbiosis of an ancestral cyanobacterium and a primitive eukaryotic cell. The two envelope membranes, outer (OE), and inner (IE) ones are homologous to external and plasma membranes of Gram-negative bacteria, which is confirmed by the presence of galactolipids and $\beta$-barrel proteins (porins) in the $\mathrm{OE}$ and external membrane of free-living Gram-negative bacteria (Inoue, 2007; Gould et al., 2008; Breuers et al., 2011). The two envelope membranes are aligned close to each other, separated by only $1-2$ membrane thickness $(5-10 \mathrm{~nm}$ as compared to a typical chloroplast size of $3-4 \mu \mathrm{m}$ ); IE and $\mathrm{OE}$ come to even closer proximity at contact sites (Inoue, 2007). Membrane/compartment arrangements in chloroplasts are different from those in mitochondria. Whereas, the outer mitochondrial membrane may be compared with the $\mathrm{OE}$, 
the inner mitochondrial membrane combines both energycoupling and metabolite exchange functions. As the two mitochondrial membranes are mostly separated, the activity of outer and inner membrane channels could be directly studied by patch-clamp technique, using intact mitochondria or swollen mitoplasts, respectively (Szabo and Zoratti, 2014). Double-membrane bound chloroplasts represent technically a more challenging task, as will be discussed in this paper. The stroma of chloroplasts, however, may be compared with the mitochondrial matrix: it is a slightly alkaline (compared to the cytosol) compartment with a high biosynthetic potential. Nine out of twenty essential amine acids are synthesized exclusively in the stroma, as well as are fatty acids, carbohydrates and triose phosphates, NADPH, purines, and a variety of secondary metabolites (Breuers et al., 2011; Rolland et al., 2012). The inner envelope contains a variety of solute transporters, mediating export of photoassimilates and import of substrates, as well as ion exchange (Weber and Linka, 2011). Both functions can be complemented by the activity of inner envelope ion channels. In addition, as it will be discussed in this review, cation channels, a putative $\mathrm{H}^{+}$-ATPase, and monovalent cation $/ \mathrm{H}^{+}$exchangers of the IE could assist maintenance of metabolically optimal alkaline $\mathrm{pH}$ in the stroma and control chloroplast volume. In the OE, transport activity of porin-like channels appears to dominate in both ion and metabolite traffic (Duy et al., 2007) and their differential substrate selectivity and regulation will be discussed.

The thylakoid membrane is an internal membrane of the chloroplast, representing a complex network of grana stacks connected by stromal lamellae (for thylakoid structure, see recent review by Pribil et al., 2014). The thylakoid membrane, being a site for light-driven photosynthetic reactions, harbors photosynthetic pigments and protein complexes of the electron transfer chain as well as F-type $\mathrm{H}^{+}$-ATPase, which performs photophosphorylation. In variance to mitochondria, chloroplasts store a proton-motive force (p.m.f.), which fuels the ATP-synthesis, mainly as $\Delta \mathrm{pH}$ rather than the transmembrane electric potential difference $(\Delta \Psi)$. Thus, thylakoid lumen represents a unique acidic compartment. Interconversion between $\Delta \mathrm{pH}$ and $\Delta \Psi$ across the thylakoid membrane is under environmental control and the steady state p.m.f. partitioning critically depends on the activity of thylakoid ion channels (Kramer et al., 2004). Partial dissipation of $\Delta \Psi$, generated by light-driven $\mathrm{H}^{+}$-pumping into thylakoid lumen is achieved via passive fluxes of anions $\left(\mathrm{Cl}^{-}\right), \mathrm{K}^{+}$, and $\mathrm{Mg}^{2+}$ (Hind et al., 1974). Accordingly, activities of anion and nonselective cation channels were revealed by direct patch-clamping of native thylakoid membranes, whereas activity of thylakoid $\mathrm{K}^{+}$-selective channels was assayed in a reconstituted system (Figure 1). Specific functional properties of these channels will be discussed in the following.

This review is centered in chloroplast ion channels, which could be directly measured by patch-clamp technique. For a broader overview of the chloroplast ion transport system in the physiological context an interested reader could consult a recent review by Pottosin and Shabala (2015).

\section{ION TRANSPORT ACROSS THE THYLAKOID MEMBRANE}

\section{Ion Fluxes Assist the Conversion of Electrical Potential Difference to $\Delta \mathrm{pH}$}

The difference of electrochemical potential for $\mathrm{H}^{+}\left(\Delta \mu \mathrm{H}^{+}\right)$, generated under light, is an obligatory intermediate for the photo-phosphorylation, ATP synthesis by $\mathrm{H}^{+}$-transporting $\mathrm{F}$ type ATPase. Often, instead of $\left(\Delta \mu \mathrm{H}^{+}\right)$, the related parameter, proton-motive force (p.m.f.) is used, p.m.f. $=\Delta \Psi-\mathrm{Z} \Delta \mathrm{pH}$ (Mitchell, 1966), where $\mathrm{Z}$ is approximately $59 \mathrm{mV}$ at room temperature, $\Delta \Psi$ and $\Delta \mathrm{pH}$ represent the differences in electrical potential and $\mathrm{pH}$ across the thylakoid membrane, respectively. Thermodynamically, electrical and chemical components of the p.m.f. are equivalent; however, measurements of turnover rates with isolated F-ATPases demonstrated that the mitochondrial and bacterial F-ATPases critically require the presence of a substantial $\Delta \Psi$, whereas chloroplast F-ATPase depends on the $\Delta \Psi$ less critically (Fischer and Gräber, 1999; Cruz et al., 2001). It was considered for a long time that under a steady state light the p.m.f. in chloroplasts consists almost completely of $\Delta \mathrm{pH}$, whereas the steady state $\Delta \Psi$ is negligibly small ( $-10 \mathrm{mV}$ stroma negative) (e.g., Bulychev et al., 1972; Remiš et al., 1986). In vivo studies, however, demonstrated that $\Delta \Psi$ may yield up to $50 \%$ of p.m.f. or $-60 \mathrm{mV}$ (Cruz et al., 2001; Kramer et al., 2003, 2004; Klughammer et al., 2013). Thus, $\Delta \mathrm{pH}$, which yields at least a half of the p.m.f., is about $1-1.5 \mathrm{pH}$ units under light. Assuming a constant stromal $\mathrm{pH}$ of 8 under light (see the section on stromal $\mathrm{pH}$ control), this yields $\mathrm{pH}$ 6.57 in the lumen. Under extreme conditions (strong light, low $\mathrm{CO}_{2}$ ), luminal pH may drop to 6-5.5 (Tikhonov et al., 1981; Schönknecht et al., 1995; Takizawa et al., 2007). On one side, an acidic $\mathrm{pH}$ in the lumen is necessary for the stimulation of non-photochemical quenching, which prevents the photodamage of the reaction center of the Photosytem II (PSII) and reactive oxygen species (ROS) generation at excessive light. On the other side, a luminal $\mathrm{pH}$ below 6.5 strongly reduced the linear electron transport flow from the cytochrome b6f complex to the reaction center of Photosystem I (PSI), and a $\mathrm{pH}$ below 6 may even cause a loss of function of the water-splitting complex (exclusive electron donor for the PSII) and of the plastocyanin, electron carrier between b6f and Photosystem I, due to the replacement of the functionally important $\mathrm{Ca}^{2+}$ and $\mathrm{Cu}$ in these proteins by protons (Kramer et al., 2003). Obviously, partitioning of p.m.f. into $\Delta \Psi$ and $\Delta \mathrm{pH}$ should be finely tuned. Existence of a (stroma) negative steady-state $\Delta \Psi$ under light implies a driving force for anion efflux from and cation influx to the stroma. If the thylakoid membrane conductance for physiologically abundant cations or anions were large, $\Delta \Psi$ will collapse, and excessive lumen acidification will result. As it did not happen, one has to assume that the functional expression of respective ion channels, their selective permeability, the availability of transported ions, and the control of channels' open probability by physiologically relevant factors (membrane voltage, $\mathrm{pH}, \mathrm{Ca}^{2+}$, etc.) should be set exactly to balance the light-driven $\mathrm{H}^{+}$pump-generated current at given $\Delta \Psi$ and $p H$ 


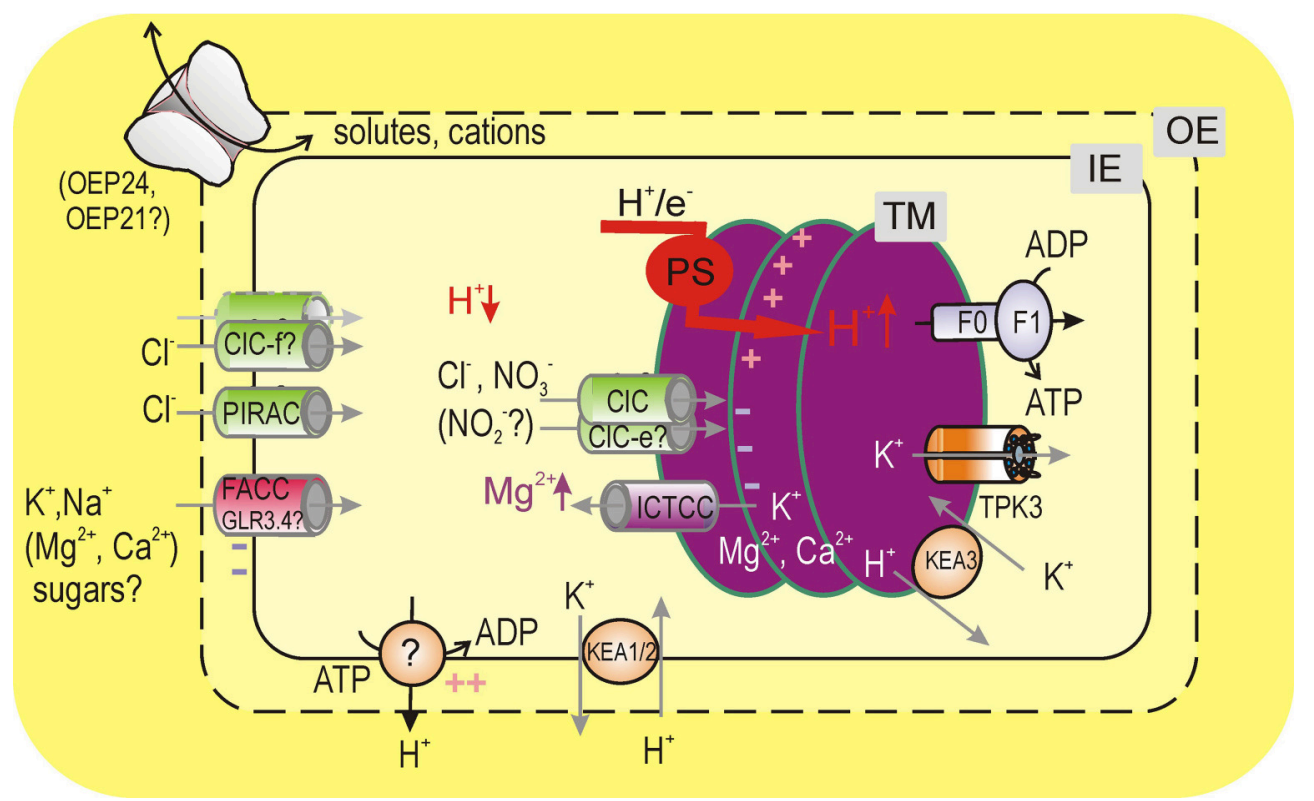

FIGURE 1 | Chloroplast ion transport under the light. Light-driven export of $\mathrm{H}^{+}$into the thylakoid lumen by photosynthetic electron transfer chain (PS) causes a hyperpolarization of the thylakoid $\Delta \Psi$. At steady state, this voltage difference is partly dissipated by channel-mediated fluxes of anions, $\mathrm{K}^{+}$, and Mg ${ }^{+}$. Light-driven $\mathrm{H}^{+}$and parallel $\mathrm{Cl}^{-}$fluxes to the thylakoid lumen cause the depletion of these ions in stroma, which is compensated by their uptake across the envelope. For maintenance of alkaline stromal $\mathrm{pH}, \mathrm{H}^{+}$could be actively extruded to cytosol by the IE $\mathrm{H}^{+}$pump, which requires a counter influx of monovalent cations across the envelope for electrical balance. $\mathrm{K}^{+} / \mathrm{H}^{+}$exchange across the envelope is essential for control of the chloroplast volume and stromal pH. Abbreviations: $\mathrm{TM}$, IE, and OE are thylakoid, inner envelope, and outer envelope membranes, FOF1 is thylakoid ATP-synthetase (F-type $\mathrm{H}^{+}$-ATPAse), TPK3 (tandem-pore $\mathrm{K}^{+} 3$ channel, functionally characterized in recombinant system). In situ functionally (by patch-clamp) detected channels were: CIC (anion-selective channel from a CIC family), ICTCC (intermediate-conductance thylakoid cation channel), FACC (fast activating chloroplast cation channel), PIRAC (protein import related anion channel), and outer envelope porins (most possibly, active OEP24 or OEP21). Other: GLR3.4 (glutamate receptor type 3.4 channel) and KEA1/2 (cation/proton antiporters from family 2, CPA2). Another member of the CPA2 family, the thylakoid-localized KEA3, accelerates dissipation of the transthylakoid $\Delta \mathrm{pH}$ upon the light offset.

in stroma and lumen. Current, generated by the light-driven $\mathrm{H}^{+}$pump (photosynthetic electron transfer chain), was directly evaluated by patch-clamp technique and could reach up to tens of pA for a single chloroplast under strong light (Bulychev et al., 1992; Muñiz et al., 1995). Above considerations emphasize the importance of quantitative measurements of the activity of thylakoid ion channels in situ, under conditions close to the physiological ones.

\section{Patching of Thylakoids is Technically Challenging but Feasible}

First patch-clamp recording on the photosynthetic membrane was achieved by Schönknecht et al. (1988), who employed hypotonic shock to inflate the thylakoid compartment. Chloroplasts, poised into the hypotonic medium (isotonic saline, diluted 4-5 times with pure water) rapidly broke down, releasing large $(10-40 \mu \mathrm{m}$ in diameter) transparent vesicles (blebs), which are swollen thylakoids. Such a large size of blebs is a consequence of the interconnection of all thylakoids within the network, which encloses therefore a common lumen (Schönknecht et al., 1990; Shimoni et al., 2005). Thylakoid blebs conserved light-induced membrane polarization, photochemical activity, and are able to photophosphorylate (Campo and Tedeschi, 1985; Allen and Holmes, 1986; Hinnah and Wagner, 1998). Forming of a high-quality gigaOhm seal between glass microelectrode and bleb represented, however, a major problem, which may be at least partially caused by a very low free lipid and high protein content of the thylakoid membrane. Together with another energy-coupling membrane, the inner mitochondrial one, thylakoids display the highest protein to lipid ratio of 3.4:1 (w/w); lipids cover only $20 \%$ of the membrane surface and $60 \%$ of total lipid is immobilized within the first protein solvation shell (Kirchhoff et al., 2002; Kirchhoff, 2008). In comparison, the outer and inner chloroplast envelope membranes present a protein to lipid w/w ratio of $0.35: 1$ and 1.1:1, respectively (Inoue, 2007). Abundance of integral proteins, protruding far from the bilayer (e.g., F-type $\mathrm{H}^{+}$-ATPase), which have to denaturate against the glass, to allow direct contact between glass and lipid, would at least make the overall sealing process longer (Suchyna et al., 2009). Yet, although the inner mitochondrial membrane displays the same high protein to lipid ratio, respective studies greatly outnumber those available so far for thylakoids (Schindl and Weghuber, 2012; Szabo and Zoratti, 2014). The difference in lipid composition of the two membranes may be an additional problem. The mitochondrial inner membrane, similar to the plasma membrane, endoplasmic reticulum, Golgi, and endosomal membranes, is rich in phospholipids, including a high percentage (about 20\%) of negatively (2-) charged cardiolipin (diphosphatydyl glycerol), specific for mitochondria (van Meer et al., 2008). Contrary to this, the thylakoid membrane is mainly 
made of galactolipids (84\%), with $7 \%$ of negatively charged sulfolipids and phosphatydylglycerol as a sole phospholipid (Block et al., 2007). The adhesion energy between glass and lipid bilayer varies by up to one order of magnitude as a function on the lipid composition (Ursell et al., 2011). This has been proven for different combinations of phospholipids, while respective data for galactolipids is missing. However, as gigaOhm seal formation is mainly stabilized by van der Waals forces (Suchyna et al., 2009), the presence of fixed dipoles in phospholipids as compared to glycolipids, would facilitate a tight seal formation in the first case. Although the first successful patch-clamp study was performed on a species with abnormally large (up to $40 \mu \mathrm{m}$ in diameter) chloroplasts, Peperomia metalica (Schönknecht et al., 1988), bleb size does not appear to be a problem for tight sealing with a patch-pipette tip. Moreover, in our hands, blebs originated from Peperomia chloroplasts were proven to be more difficult to patch as compared to more typical chloroplasts of spinach. A critical moment was the time spent between a bleb formation in the experimental chamber and the attempt to obtain a tight seal, which should not exceed 10-15 min. (Pottosin and Schönknecht, 1995a, 1996; Hinnah and Wagner, 1998). Failure in fulfilling this condition resulted in the absence of stable tight seals (Enz et al., 1993). The presence of high divalent cation concentrations (e.g., $5 \mathrm{mM} \mathrm{MgCl}$ ) at both membrane sides was also mandatory. It should also be noted that albeit achievement of high (up to $10 \mathrm{GOhm}$ ) resistance seals between the patch pipette and a thylakoid bleb could be done routinely, obtained membrane patches were extremely fragile and rarely withstood voltages higher than $40 \mathrm{mV}$ by absolute value. So far, any attempt to get access to the bleb interior (whole thylakoid configuration) by application of a short pulse of high voltage or of strong suction resulted in the loss of the sample in $100 \%$ of cases. Yet, a very promising perspective to gain low resistance access to the thylakoid lumen without loss of a tight seal may be patch perforation by incorporation of channel-forming antibiotics (e.g., gramicidin, Schönknecht et al., 1990) into the patch pipette tip.

An alternative for a direct patch-clamping of the intact thylakoid membrane could be a dilution of the thylakoid lipid, either by its fusion into azolectin liposomes (Enz et al., 1993) or by incorporation of thylakoid membranes or purified channel protein into artificial lipid bilayers (Tester and Blatt, 1989; Li et al., 1996; Carraretto et al., 2013). Yet, it should be noted that incorporation of any external material into the lipid bilayer could produce an artificial channel. This may not necessarily be a protein responsible for such activity, as defects caused by lipid peroxidation, detergents, and/or bacterial contamination could be equally problematic (Labarca and Latorre, 1992; Pelzer et al., 1993). Consequently, one needs to have additional criteria. Usage of specific channel agonists or antagonists should be a solution, but as far as we know such a test was not performed for thylakoid channels, and even reproducibility of channel characteristics may be considered a problem in this case. This is not surprising, as an artificial environment can alter the channels' function or even induce a channel-like behavior in proteins, which do not form channels under physiological conditions, as it is true, for instance, for the chloroplast triose phosphate/phosphate translocator or phosphate carrier of inner mitochondrial membrane (Schwarz et al., 1994; Herick et al., 1997).

\section{Anion-Selective Channel: Evidence for a Functional $\mathrm{CIC}$ in the Thylakoid Membrane}

A $100 \mathrm{pS}$ (in $100 \mathrm{mM} \mathrm{KCl}$ ) voltage-dependent channel, with almost perfect selectivity for anions $\left(\mathrm{Cl}^{-}, \mathrm{NO}_{3}^{-}\right)$over $\mathrm{K}^{+}$ was first time reported for intact thylakoid membrane from chloroplasts, isolated from leaves of $P$. metalica (Schönknecht et al., 1988). Later on, quite similar in their conductance (Figure 1), selectivity, and voltage-dependent kinetics channels were reported also for thylakoids of a Charophyte alga Nitellopsis obtuse and spinach (Pottosin and Schönknecht, 1995a,b). Notably, no such channel could be detected upon reconstitution of spinach thylakoid membranes into giant azolectin liposomes (Enz et al., 1993), which emphasizes the importance of studies on native membranes. Thylakoid anion channel by its conductance is reminiscent of the so-called "mitochondrial Centium picoSiemens" (mCS) anion channel of the inner membrane. Yet, mCS channel has a low $\mathrm{Cl}^{-} / \mathrm{K}^{+}$ selectivity, is inhibited by $\mathrm{Mg}^{2+}$, and has a distinct voltage dependence (Sorgato et al., 1987; Borecký et al., 1997; Tomaskova and Ondrias, 2010; Szabo and Zoratti, 2014) as compared to the thylakoid channel. The voltage dependence of the thylakoid anion channel was bell-shaped, with a maximal open probability at zero voltage and a steep decrease of it at both positive and negative potentials, so that at $\pm 50 \mathrm{mV}$ the steady open probability was close to zero (Pottosin and Schönknecht, 1995a, 1996). Increase of $\mathrm{Cl}^{-}$concentration on the luminal side tended to increase the channel's open probability, which may serve as a positive feedback mechanism upon light-induced anion accumulation in thylakoids (Pottosin and Schönknecht, 1995a). It has been shown that the thylakoid anion channel voltagedependence is controlled by the two gating processes: a rapid (ms) one, which tends to favor open probability at stromapositive potential, and a slow (sub-seconds to seconds), which, in contrast, favors the channel opening at stroma-negative potentials. Consequently, changing the voltage polarity evoked transient channel openings, relaxing slower when the potential was switched from positive to negative values (Schönknecht et al., 1988; Pottosin and Schönknecht, 1995a). Change of the polarity of transthylakoid $\Delta \Psi$ naturally occurs upon light-dark transitions, with the light onset or offset making stromal side more negative (Figure 1) or positive, respectively (Kramer et al., 2003). In this context, transient "on demand" activation of the anion channel may be especially important upon the light onset, when the channel-mediated current will accelerate the achievement of a steady state $\Delta \Psi$ at the light. Often, thylakoid patches displayed the activity of multiple anion channels. Whereas, fast close-open transitions of these channels were independent each of other, a common slow gate was detected, which could close a pair of channels simultaneously, with a probability far above being merely a coincidence (Pottosin and Schönknecht, 1995a). Thus, thylakoid anion channels displayed a coupled ("double-barreled") behavior, which is a hallmark characteristic for anion channels from the $\mathrm{ClC}$ family. 
The $\mathrm{ClC}$ family is dominated by $2 \mathrm{Cl}^{-} / 1 \mathrm{H}^{+}$antiporters, and only a small part of it displays channel-like behavior. Such "broken" transporters preserve the activation by external protonation and have some remnant permeability to $\mathrm{H}^{+}$, which drives their slow gating cycle out of equilibrium (Miller, 2006; Zifarelli and Pusch, 2010a,b). ClC channels and transporters, however, present only minor structural differences. A ClC protein possesses two homologous extended $\mathrm{Cl}^{-}$pathways, which may be locked open in channels, resulting in long-living transmembrane pores. The presence of those two homomeric $\mathrm{Cl}^{-}$pores, whose opening may be controlled by a common gate, serves as a natural explanation for a "double-barreled" behavior. In the $\mathrm{ClC}$ transporter structure, two glutamate residues, external, and internal ones, are essential for $\mathrm{H}^{+}$sensing and transport, respectively. Consequently, channel members of ClC family lack the " $\mathrm{H}^{+}$transport" glutamate, but preserve the external one, controlling the fast gate (Miller, 2006; Zifarelli and Pusch, 2010a). In Arabidopsis, of seven ClC members only two, AtClC-e and AtClC-f, are potentially channel-forming, according to this criterion (Zifarelli and Pusch, 2010a). A ClC$\mathrm{f}$ product was localized in the outer chloroplast envelope and in Golgi membranes, whereas $\mathrm{ClC}$-e is targeted at the thylakoid membrane (Teardo et al., 2005; Marmagne et al., 2007). One problem, however, is related to these tentative ion channels: they are lacking a highly conserved sequence, underlying $\mathrm{Cl}^{-}$(GSGIP) or $\mathrm{NO}_{3}^{-}$(GPGIP) selectivity: in ClC-e and $-\mathrm{f}$ these are replaced by ESAGK and EILDQ, respectively. Thus, current state-of-art approaches may not predict to which selectivity this arrangement may account (Zifarelli and Pusch, 2010a). The knockout of either of these genes disturbed nitrate homeostasis, although it remains unclear, whether it was a consequence of the cessation of $\mathrm{NO}_{3}^{-}$ and/or or $\mathrm{NO}_{2}^{-}$transport by these channels, because multiple parameters were affected, including decrease of nitrate uptake by roots and expression of high-affinity nitrate transporters, increased nitrite and decreased nitrate levels (Monachello et al., 2009).

Unanswered questions include before all an unambiguous identification of the thylakoid anion channel. If it is ClC-e, as proposed by us and by others (Checchetto et al., 2013; Pfeil et al., 2014), then a direct proof should be the presence or absence of anion channels activity in thylakoids of WT and knock-out plants, respectively. This reinforces the need of a direct patchclamping of Arabidopsis thylakoids, the problem is technically not solved yet, but is definitely a rewarding one. Lack of $\mathrm{ClC}-\mathrm{e}$ function plants did not show a clear phenotype (Marmagne et al., 2007), but p.m.f. partitioning was not addressed so far, which calls for a further study. We also believe that testing the $\mathrm{pH}$ regulation of the thylakoid anion channel activity is physiologically quite relevant, due to the large changes of luminal and stromal $\mathrm{pH}$ upon dark/light transitions and due to the existence of a strong regulation of ClC-type channels by protons. Finally, although up to now no specific blocker of ClC channels is known, nonspecific blockers like 9-anthracene carboxylate, flufenamic or niflumic acid, and clofibric acid derivates are available (Zifarelli and Pusch, 2012) and should be tested directly against thylakoid anion channels, to reveal their potential for further usage in diverse functional assays (e.g., p.m.f. steady state partitioning).

\section{DIVALENT CATION-PERMEABLE CHANNELS}

$\mathrm{Mg}^{2+}$ influx from thylakoids into stroma is recognized as a part counterbalancing process for light-driven $\mathrm{H}^{+}$transport into the lumen for a long time, although its contribution decreases upon the increase of external (cytosolic) $\mathrm{K}^{+}$(Hind et al., 1974). However, light onset caused a very substantial increase of stromal $\mathrm{Mg}^{2+}$, from $0.5-1$ to 2-3 mM (Portis and Heldt, 1976; Ishijima et al., 2003). Given relatively low envelope permeability for $\mathrm{Mg}^{2+}$ (Gimmler et al., 1974), this change is due to the mobilization of $\mathrm{Mg}^{2+}$ from thylakoids. It should be noted that as specific volumes of thylakoids to stroma are related as 1:15 (Heldt et al., 1973), a $2 \mathrm{mM}$ increase of stromal $\mathrm{Mg}^{2+}$ implies a decrease of total thylakoid $\mathrm{Mg}^{2+}$ concentration by $30 \mathrm{mM}$. This suggests the involvement of a high capacity $\mathrm{Mg}^{2+}$-transporting system in the thylakoid membrane, most likely an $\mathrm{Mg}^{2+}$-permeable channel (Figure 1).

Patch-clamp study of Pottosin and Schönknecht (1996) revealed the presence of a non-selective cation channel in $75 \%$ of patches, derived from intact spinach thylakoids. This (here: ICTCC) intermediate conductance (55 pS in symmetric $100 \mathrm{mM} \mathrm{KCl}$ ) thylakoid channel was virtually impermeable for $\mathrm{Cl}^{-}$, and has a lower conductance, but comparable relative permeability for $\mathrm{Ca}^{2+}$ and $\mathrm{Mg}^{2+}$ as compared to $\mathrm{K}^{+}$. ICTCC appears to be relatively robust, as similar channel activity could be registered also upon reconstitution of spinach thylakoids in giant liposomes or artificial bilayers (Enz et al., 1993; Li et al., 1996). A similar channel was also reported in a direct patchclamp study on swollen thylakoids from pea leaves (Hinnah and Wagner, 1998). ICTCC was weakly voltage-dependent, with an increase of open probability from 0.1 at -50 to $\sim 0.5$ at $+50 \mathrm{mV}$ (stroma minus lumen). Thus, under light conditions (stromal side made more negative, voltage gradually declining to a steady state), time-averaged current through a single ICTCC would be approximately constant $(\sim-0.3 \mathrm{pA})$, as a decrease of electrical driving force would be compensated by the increase of open probability (Pottosin and Schönknecht, 1996). As a permeability of ICTCC for $\mathrm{K}^{+}$and $\mathrm{Mg}^{2+}$ is comparable, ICTCC-mediated $\mathrm{K}^{+}$ and $\mathrm{Mg}^{2+}$ fluxes ratio will be determined by the ratio between luminal $\mathrm{K}^{+}$and $\mathrm{Mg}^{2+}$ activities. Assuming that it is $10: 1$, which is probably an upper estimate for the $\mathrm{Mg}^{2+}$ flux fraction, a single ICTCC will increase total stromal $\mathrm{Mg}^{2+}$ by $1 \mathrm{mM}$ in just $20 \mathrm{~s}$. Free stromal $\mathrm{Mg}^{2+}$ increased by $1 \mathrm{mM}$ in the light in 5$10 \mathrm{~min}$ (Ishijima et al., 2003). However, only $5 \%$ of the chloroplast $\mathrm{Mg}^{2+}$ is free, whereas $95 \%$ is bound to the thylakoid surface, phosphorylated compounds and dicarboxylates (Portis, 1981). Therefore, the ICTCC-mediated $\mathrm{Mg}^{2+}$ flux may account for observed light-induced increase in stromal free $\mathrm{Mg}^{2+}$. A curious feature of the light-induced $\mathrm{Mg}^{2+}$ influx to the stroma is its insensitivity to $\mathrm{La}^{3+}$ and a high sensitivity to ruthenium red (Ishijima et al., 2003), which should be addressed by a direct test with ICTCC.

A light-induced increase of free stromal $\mathrm{Mg}^{2+}$, although not being large by absolute value, is essential for activation of the two key enzymes of $\mathrm{CO}_{2}$ fixation cycle, fructose -1,6bisphosphatase (FBPase) and sedoheptulose-1,7- bisphosphatase, 
SBPase (Portis et al., 1977; Hertig and Wolosiuk, 1980; Wolosiuk et al., 1982). $\mathrm{Mg}^{2+}$-deficient plants are characterized by extreme light sensitivity and chlorotic lesions. This was associated with the impairment of the $\mathrm{CO}_{2}$ fixation cycle, limiting the overall photosynthetic rate, over-reduction of the electron transport chain, and consequent photodamage due to ROS accumulation (Cakmak and Kirkby, 2008). So far, ICTCC represents the only known $\mathrm{Mg}^{2+}$-permeable channel in thylakoids. Important regulatory role of light-induced $\mathrm{Mg}^{2+}$ increase on stromal metabolism calls for further studies on the ICTCC molecular identity, distribution, pharmacology, and functional contribution (e.g., existence of alternative ways of $\mathrm{Mg}^{2+}$ shuttling between cytosol and stroma).

A separate, potentially more important perspective for ICTCC, is related to its $\mathrm{Ca}^{2+}$-permeability. In the last years, ample evidence for the accompaniment of responses to different stresses of the cytosolic $\mathrm{Ca}^{2+}$ signal by stromal $\mathrm{Ca}^{2+}$ increase has been obtained (Nomura and Shiina, 2014). Moreover, in several occasions stromal $\mathrm{Ca}^{2+}$ occurred simultaneously to cytosolic $\mathrm{Ca}^{2+}$ increase or even preceded it (Nomura et al., 2012). Stromal $\mathrm{Ca}^{2+}$ may be increased by a voltage-driven uniport across the envelope from the cytosol (Roh et al., 1998). As at the rest cytosolic and stromal $\mathrm{Ca}^{2+}$ levels are approximately the same, $\sim 150 \mathrm{nM}$ (Johnson et al., 1995), $\mathrm{Ca}^{2+}$ uptake into stroma requires a negative potential difference across the envelope, which is the case, especially under light (see below). However, this route may have its limitations. For instance, although lightinduced $\mathrm{Ca}^{2+}$ uptake to the stroma was readily recorded (Muto et al., 1982), this did not lead to a measurable stromal free $\mathrm{Ca}^{2+}$ increase, due to increased stromal $\mathrm{Ca}^{2+}$ buffering capacity at more alkaline $\mathrm{pH}$ on the light and/or efficient $\mathrm{Ca}^{2+}$ uptake by energized thylakoids, which occurs via $\mathrm{Ca}^{2+} / \mathrm{H}^{+}$antiport mechanism (Ettinger et al., 1999). So, alternatively, passive $\mathrm{Ca}^{2+}$ release from thylakoid lumen to stroma may be considered as a cause of a stromal $\mathrm{Ca}^{2+}$ signal. A possible role of ICTCC in it requires further elucidation.

\section{OTHER CHANNELS}

Light-induced $\mathrm{K}^{+}$influx into the stroma, together with anion efflux via anion-selective channels of the thylakoid membrane, is indisputably important for electric balance of the light-driven $\mathrm{H}^{+}$uptake by thylakoids, especially at physiologically relevant $\mathrm{K}^{+}$concentrations (Hind et al., 1974). Activity of thylakoid anion or cation channels, due to the opposite direction of respective ion fluxes, will cause thylakoid swelling or shrinkage under light. Thus, volume control may be one of the reasons for the implementation of approximately equivalent fluxes of cations and anions across the thylakoid membrane (Figure 1). The activity of ICTCC may be relevant for a mediation of the light-induced $\mathrm{K}^{+}$flux, but perhaps insufficient, as the whole thylakoid cation current has to be in the range of several pA. Recently, a tandem-pore $\mathrm{K}^{+}$-selective channel (TPK3) was localized in Arabidopsis stromal thylakoid lamellae (Carraretto et al., 2013). Silencing of TPK3 resulted in Arabidopsis plants with reduced growth and altered thylakoid morphology. More specifically, TPK3-silenced plants displayed a reduced nonphotochemical quenching, due to a decrease of a steady state $\Delta \mathrm{pH}$ between stroma and lumen (hence, more alkaline luminal $\mathrm{pH})$. Thus, TPK3 has a strong impact on the steady state p.m.f. partitioning at the light. Preliminary characterization revealed that recombinant TPK3 forms a voltage-independent $\mathrm{Ba}^{2+}$ sensitive and $\mathrm{TEA}^{+}$insensitive channel, with a conductance of $\sim 30 \mathrm{pS}$. It conducts $\mathrm{K}^{+}$, but seems to be not perfectly selective for $\mathrm{K}^{+}$over $\mathrm{Cl}^{-}$and its relative selectivity for physiologically relevant cations is unknown. TPK3 likely requires $\mathrm{Ca}^{2+}$ for its activity, but whether it is regulated by $\mathrm{Ca}^{2+}$ within its physiological range of free concentrations remains to be elucidated. It is instructing that two other explored members of TPK family in Arabidopsis, TPK1, and TPK4, are activated by cytosolic $\mathrm{H}^{+}$(Allen et al., 1998; Becker et al., 2004). Preliminary data by Carraretto et al. (2013) demonstrated a strong stimulation of the reconstituted TPK3 by the acidification from $\mathrm{pH} 7.4$ to 6.75 , but the sidedness of the effect is unclear. Bearing the large changes of $\mathrm{pH}$ in stroma and lumen upon light-dark transitions in mind, the $\mathrm{pH}$-dependence of TPK3 should be addressed. Last, but not least: it is highly desirable to demonstrate the TPK3 activity in situ, i.e., in thylakoid blebs of Arabidopsis.

For the sake of completeness, an electroneutral (hence, not detectable by the patch-clamp) $\mathrm{K}^{+} / \mathrm{H}^{+}$antiporter KEA3, localized in the thylakoid membrane, should be considered (Figure 1). It works oppositely to TPK3, reducing the $\Delta \mathrm{pH}$ gradient across the thylakoid membrane and takes $\mathrm{K}^{+}$up into the lumen (Kunz et al., 2014). Its activity is very essential upon naturally occurring intermittent light conditions. Specifically, upon the transition from a high to a low light condition, KEA3 accelerates the $\Delta \mathrm{pH}$ dissipation and luminal $\mathrm{pH}$ increase, which led to the recovery of the photosystem II quantum efficiency (Armbuster et al., 2014). The presence of two $\mathrm{K}^{+}$transporting systems, TPK3, and KEA3, mediating $\mathrm{K}^{+}$transport in opposite directions and oppositely affecting the lumen acidification is analogous to the presence of a $\mathrm{K}^{+}$-permeable channel and $\mathrm{KEA} 1 / 2$ in the inner envelope (see below); a balance between their opposite activities is essential for the chloroplast volume regulation and $\mathrm{pH}$ homeostasis (Kunz et al., 2014).

\section{ENVELOPE ION AND SOLUTE CHANNELS}

\section{Outer Envelope Contains Large-Conductance Porins}

Outer envelope (OE) is an important interface between cytosol and chloroplast. The classical view on $\mathrm{OE}$ is that it is a low selective molecular sieve, which is freely permeable to small molecules and proteins with molecular weights of up to $10 \mathrm{kDa}$ (Flügge and Benz, 1984). This view could be reconsidered, however, in light of finding of relatively high cation-selective $\left(\mathrm{P}_{\mathrm{K}+} / \mathrm{P}_{\mathrm{Cl}-}=14\right)$ porin-like channels OEP23 and OEP37 (Goetze et al., 2006, 2015), and OEP16, a large conductance channel with a striking substrate selectivity for amines and amine acids (Pohlmeyer et al., 1997; Steinkamp et al., 2000; Duy et al., 2007; Pudelski et al., 2010). Moreover, OEP16 excludes sugars, which, basing on their size should pass the channel pore if it was a simple 
sieve (Pohlmeyer et al., 1997). It was demonstrated for at least one OEP16 isoform, OEP16.2, preferentially expressed in seeds, that its lack of function caused a metabolic imbalance (primarily, changes in free amino acid contents), ABA-hypersensitivity, and early germination (Pudelski et al., 2012). It is also notable, that a relatively weakly selective OEP21 could change its rectification and ionic selectivity from weakly anionic to cationic one upon binding of ATP and phosphorylated carbohydrates exclusively from the intermembrane space (Bölter et al., 1999). This fact argues for a possibility that $\mathrm{OE}$ may exert barrier functions for a metabolite exchange between chloroplast and the rest of the cell (Flügge, 2000; Soll et al., 2000; Breuers et al., 2011). As it follows then, the intermembrane space between $\mathrm{OE}$ and inner envelope (IE) may represent a compartment on its own, with properties different from those of cytosol. Finally, OEP24 represents the only porin with a low ion selectivity and a broad range of transporting substrates, including amino acids, sugars, and phosphorylated sugars, dicarboxylates, ATP, and inorganic cations (Bölter et al., 1999). It appears that OEP24 relative expression is correlated with a requirement of a higher metabolic flux across the envelope (Bräutigam et al., 2008; Breuers et al., 2011), at which condition its function could not be compensated by higher selective porins. Interestingly, upon heterologous expression in yeast, OEP24 is targeted to the outer envelope membrane of mitochondria, where it can compensate the lack of function of the VDAC (Röhl et al., 1999), principle mitochondrial porin, which controls ions and metabolite traffic across the outer mitochondrial membrane (Colombini, 2012a). Most of the OE porins display bell-shaped voltage dependence, being open at voltages close to zero and closing at large potentials of either sign (Pohlmeyer et al., 1997, 1998; Bölter et al., 1999; Goetze et al., 2006). It is believed that this property does not have a physiological importance, as there is no potential drop across the OE except for a (supposedly small) Donnan potential difference due to accumulation of large weakly permeable anionic species in the intermembrane space. There are some studies for mitochondria, however, which estimate the Donnan potential difference could be as large as $20-40 \mathrm{mV}$ (cytosol positive; Porcelli et al., 2005). At $+25 \mathrm{mV}$ VDAC is switched to a subconductance state, and VDAC-mediated ATP transport stops (Colombini, 2012b). A similar situation may exist with OEP21, which is blocked by ATP and at the same time seems to transport it in a "tight fit manner" (Hemmler et al., 2006). Notably, OEP21 has the steepest voltage dependence among chloroplast porins, which is similar to that of VDAC, and at large potentials it is switched to a subconductance state of about $20 \%$ of maximal conductance (Bölter et al., 1999). A maximum of time-averaged conductance for OEP21 is observed at $+25 \mathrm{mV}$, whereas at zero voltage it is close to minimal one. Therefore, for this porin, in contrast to other OEPs, it would be essential, whether the voltage difference across the OE is zero or $+25 \mathrm{mV}$ (the value, close to that for the Donnan potential difference in mitochondria).

Proteomic analysis of the $\mathrm{OE}$ demonstrated that $\mathrm{OE}$ is enriched in five non-redundant transport proteins: an $\mathrm{ABC}$ transporter with unknown function and aforementioned OEP $16,21,24$, and 37 , plus a protein translocon channel, formed by TOC75 (Gutierrez-Carbonell et al., 2014). Although this list may be non-exhaustive, it can serve as a first-aid guide for the identification of porins, measured in intact chloroplast membranes. Large conductance weakly selective $\left(\mathrm{P}_{\mathrm{K}}+/ \mathrm{P}_{\mathrm{Cl}-} \sim\right.$ 2.3) porins, with a bell-shaped voltage dependence could be detected in intact chloroplasts of higher plants (Muñiz et al., 1995). All these properties are reminiscent of those for pea OEP24 (Pohlmeyer et al., 1998). Measurements on intact chloroplasts of a Charophyte alga Nitellopsis obtusa revealed two types of large-conductance porin-like channels and an anion selective channel (Pottosin, 1992). Anion selective-channel by its conductance and voltage dependence was very similar to its counterpart in the thylakoid membrane (Pottosin and Schönknecht, 1995a), albeit being less selective for $\mathrm{Cl}^{-}$over $\mathrm{K}^{+}$, $\mathrm{P}_{\mathrm{Cl}-} / \mathrm{P}_{\mathrm{K}}^{+} \sim 12$. A weakly selective anion channel with a similar conductance and identical voltage dependence was registered upon reconstitution of spinach envelope membranes into lipid bilayers (Viérick et al., 2003). These findings corroborate the report on the localization of ClC-f in the OE (Teardo et al., 2005), although an expected "double-barreled" gating of this tentative channel remains to be demonstrated functionally. The most abundant weakly selective cation porin in a Nitellopsis chloroplast was reminiscent of VDAC by its voltage dependence, substates occurrence, and effect exerted by the synthetic König's polyanion, known gating modulator of VDAC (Colombini et al., 1987; Pottosin, 1993). When compared to pea porins, its voltage-dependent behavior (position of maximum at $\sim+20 \mathrm{mV}$, steepness, closure to a subconductance state of about $20 \%$ of maximal at large potentials of either sign) better fits that of OEP21. OEP21 displayed cation selectivity only in the presence of submillimolar to low millimolar ATP in the intermembrane space (Bölter et al., 1999). Such a condition, however, might also naturally occur in experiments on intact chloroplasts on Nitellopsis. Summarizing, patch-clamp measurements on relatively large (about $10 \mu \mathrm{m}$ ) and robust chloroplasts of $N$. obtusa revealed ion channels, which, on the basis of their activity and large conductance, are more likely to be located in the OE. However, working on smaller chloroplasts from higher plants, we were forced to make different assumptions on the patch configuration upon stable recording.

\section{Is it Possible to Measure Ion Channel Activity from the Inner Envelope of an Intact Chloroplast?}

Patch-clamp measurements of porin-like channels in attached configuration on intact pea chloroplasts could be done only within a short period, due to a spontaneous patch isolation and chloroplast lysis (Pottosin et al., 2005). Before the collapse, currents through porin-like channels were distorted and decreased in amplitude as if a membrane vesicle was formed on the tip of the pipette (Hamill et al., 1981). We believed that, due to a very close alignment of the $\mathrm{OE}$ and IE membranes ( $5 \mathrm{~nm}$ space) and existence of tight contact sites between the two envelope membranes, it was hardly possible that this vesicle was formed by the OE alone, stripped from the IE. Most likely, the sealing of the intermembrane space took place upon patch 
isolation, so that a sandwich-like arrangement of $\mathrm{OE}$ and IE resulted (Figure 2). Insulation of the transmembrane space is required for a switch of a recording on the $\mathrm{OE}$ to that on the IE. As electrical resistance of the OE, due to the presence of high conductance pores, is much lower than that of the IE, command voltage will fall mainly across the IE and the IE will limit the overall ion flux. The fraction of voltage drop across the OE would be close to zero, so porins would be mainly locked in the open state, fixing this condition over the whole experiment in insideout patch configuration. The same conclusion was drawn by van den Wijngaard and Vredenberg (1997; van den Wijngaard et al., 2000)-another group, which succeeded in stable patch-clamp recordings on the intact chloroplast envelope of pea.

\section{Fast-Activated Cation Channel in the Pea Envelope Membrane}

Spontaneous isolation of the envelope patch resulted in a quite different pattern of channels' activity. The dominant smaller conductance channels were rapidly activated $(\tau \sim 1-$ $2 \mathrm{~ms}$ ) by large membrane polarizations of either sign and were

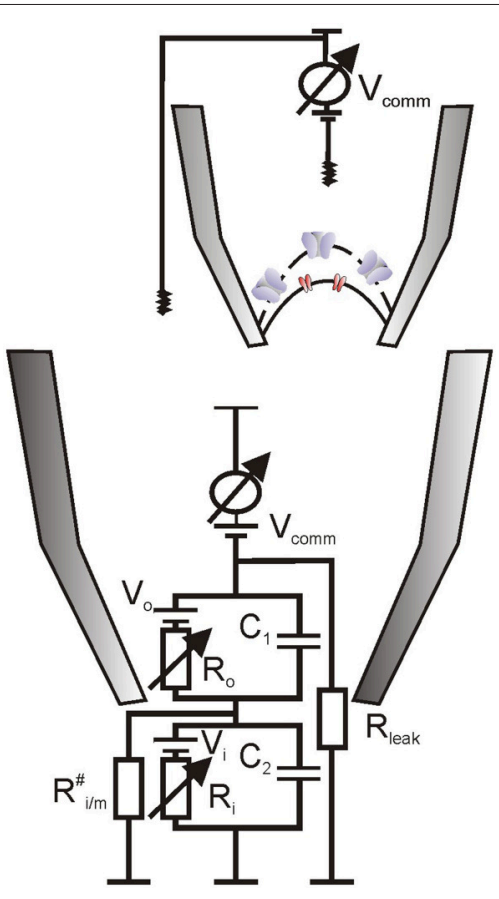

FIGURE 2 | Hypothetical equivalent electrical circuit for recording on a sandwich-like envelope patch. It is assumed that the intermembrane space was tightly sealed $\left(R_{i / m}^{\#}>>R_{0}\right)$ and that inner envelope electrical resistance was much higher than of the outer envelope, $R_{i}>>R_{0}$ (due to the presence of multiple porins in the latter), so that command voltage $\left(V_{\text {comm }}\right)$ dropped almost entirely across the inner envelope membrane patch $\left(V_{c o m m} \sim V_{i}\right)$. $R_{0}$ represents the access resistance, which was $\sim 1$ GOhm for measurements on pea chloroplasts, equivalent to a presence of few (2-3) open porins in the outer patch membrane. Average patch capacitance was about $0.35 \mathrm{pF}$; on the basis of specific capacitance for biological membranes $\left(\sim 1 \mu \mathrm{F} / \mathrm{cm}^{2}\right)$ this transforms to $35 \mu \mathrm{m}^{2}$ or $70 \%$ of the pea chloroplast surface, additional argument for the presence of a double membrane vesicle in the patch (Pottosin et al., 2005). highly selective for $\mathrm{K}^{+}$over $\mathrm{Cl}^{-}, \mathrm{P}_{\mathrm{Cl}-} / \mathrm{P}_{\mathrm{K}}^{+}<0.03$, but weakly differentiated between $\mathrm{K}^{+}, \mathrm{Na}^{+}, \mathrm{Ca}^{2+}$, or $\mathrm{Mg}^{2+}$ (Pottosin et al., 2005). It was termed FACC, for the fast activating chloroplast cation channel (Figure 1). By its permeability to divalent cations and conductance value, FACC may be compared with the glutamate receptor iGLR3 channel, which was found in the IE of Arabidopsis chloroplasts and assayed upon fusion of IE vesicles with an artificial planar lipid bilayer (Teardo et al., 2010). It should be interesting, then, to test effects of iGLR3 channel agonists and antagonists against FACC. Physiologically, FACC will mainly mediate the exchange of $\mathrm{K}^{+}$(and $\mathrm{Na}^{+}$) across the envelope, because free concentrations of $\mathrm{Ca}^{2+}$ and $\mathrm{Mg}^{2+}$ at both envelope sides are lower than those for $\mathrm{K}^{+}$by a factor of $10^{6}$ and $10^{2}$, respectively. FACC displayed a U-shaped voltage dependence of the open probability, which was reminiscent of this for so-called fast vacuolar channel, FV (Tikhonova et al., 1997). However, current via FV channel was almost completely abolished by sub- $\mathrm{mM}$ cytosolic $\mathrm{Ca}^{2+}$ or $\mathrm{Mg}^{2+}$ (Tikhonova et al., 1997; Brüggemann et al., 1999) and the FACC-mediated currents could be measured in the presence of high concentrations of these cations. Yet, a reduction of cytosolic $\mathrm{Ca}^{2+}$ from $2 \mathrm{mM}$ to physiological level of $200 \mathrm{nM}$ caused an increase of the FACC open probability almost 10 -fold in the physiological voltage range (Pottosin et al., 2005). Trans-envelope voltage difference is negative at stromal side and decreased by absolute value upon an increase of cytosolic $\mathrm{KCl}$ concentration, from $-110 \mathrm{mV}$ at $5 \mathrm{mM}$ to $-20 \mathrm{mV}$ at $-100 \mathrm{mM} \mathrm{KCl}$ under light; in dark conditions voltage difference is depolarized by $\sim 20 \mathrm{mV}$ (Demmig and Gimmler, 1983). FACC also sensed stromal $\mathrm{pH}$ changes within the range, correspondent to light- dark transition: its open probability increased several-fold upon the $\mathrm{pH}$ change from 8 to 7.3 (Pottosin et al., 2005). Such a behavior may be expected from a channel, which tended to oppose stromal acidification.

An alkaline stromal $\mathrm{pH}(\sim 8)$ is optimal for the activity of FBPase and SBPase, whereas at $\mathrm{pH}$ below 7.3 the turnover rate of the $\mathrm{CO}_{2}$ fixation cycle became very low (Werdan et al., 1975; Chardot and Meunier, 1991). Light-driven uptake of $\mathrm{H}^{+}$ and a parallel flux of $\mathrm{Cl}^{-}$across the thylakoid membrane were extended to a decrease of activity of these ions in the cytosol, a stable one for $\mathrm{Cl}^{-}$and a transient one for $\mathrm{H}^{+}$ (Thaler et al., 1991). The reversibility of the light-induced cytosol alkalinization may argue for the existence of an active mechanism of the $\mathrm{H}^{+}$extrusion from stroma across the envelope. Functional evidence suggested that $\mathrm{H}^{+}$evacuation from stroma is mediated by yet non-identified IE primary $\mathrm{H}^{+}$pump (Maury et al., 1981; Berkowitz and Peters, 1993). Function of an electrogenic $\mathrm{H}^{+}$pump will polarize the trans-envelope potential (Figure 1), which calls for a balancing counterion flux. It is long known that stromal acidification may be reversibly induced by depletion of the external medium of monovalent cations, $\mathrm{K}^{+}$ and $\mathrm{Na}^{+}$, which could act, therefore, as counterions for active $\mathrm{H}^{+}$extrusion (Demmig and Gimmler, 1983; Wu et al., 1991; Wu and Berkowitz, 1992; Heiber et al., 1995). The respective $\mathrm{K}^{+}$influx to and $\mathrm{H}^{+}$efflux from stroma are in the range of 100 and $20 \mathrm{nmol} / \mathrm{min}$ per mg of chlorophyll at 10-20 and $100 \mathrm{mM}$ external $\mathrm{K}^{+}$, respectively (Demmig and Gimmler, 1983; Wu et al., 1991); a decreased $\mathrm{K}^{+}$influx at higher external 
$\mathrm{K}^{+}$may be dealt with by a decrease of the $\mathrm{K}^{+}$-driving force (trans-envelope voltage difference). These values transform to electrical current of 0.2 and $0.04 \mathrm{pA}$ per single chloroplast; the latter value (for $100 \mathrm{mM}$ cytosolic $\mathrm{KCl}$ ) may be more physiologically relevant. At physiological $\mathrm{pH}, \mathrm{Ca}^{2+}$ and voltage a single FACC mediated $\sim 1$ pA current and had an open probability of $1-2 \%$ (Pottosin et al., 2005), which implies that a single FACC conducted the time-averaged $\mathrm{K}^{+}$current of approximately 10-20 fA. Thus, the activity of few FACC channels as typically observed in isolated chloroplast patches (Pottosin et al., 2005) might be sufficient to balance the IE pump-mediated $\mathrm{H}^{+}$extrusion. As will be discussed below, the chloroplast volume appears to be finely balanced by channel-mediated $\mathrm{K}^{+}$influx and $\mathrm{K}^{+} / \mathrm{H}^{+}$antiporters- mediated $\mathrm{K}^{+}$efflux across the envelope (Figure 1). On the quantitative basis, therefore, we believe that high-conductance and poorly regulated $\mathrm{K}^{+}$permeable channels, reported by others to be present in the IE (Mi et al., 1994), are likely artifacts of reconstitution procedures. Indeed, a single channel of this type will conduct a time-averaged current of few $\mathrm{pA}$, which is by two orders of magnitude above the demand. It will collapse the transenvelope voltage difference and will always overweight the $\mathrm{K}^{+}$flux, generated by $\mathrm{IE} \mathrm{K}^{+} / \mathrm{H}^{+}$antiporters, making their contribution to volume control insignificant and the overall function (stromal acidification) counterproductive.

An important note should be made on the thermodynamics of $\mathrm{K}^{+}\left(\mathrm{Na}^{+}\right) / \mathrm{H}^{+}$exchange across the envelope. $\mathrm{H}^{+}$extrusion from stroma to cytosol is against the $\mathrm{H}^{+}$gradient and may be only active. This active transport will fuel a downhill channel-mediated $\mathrm{K}^{+}\left(\mathrm{Na}^{+}\right)$uptake into the stroma. The direction of transports, thus, is exactly opposite to those mediated by conventional $\mathrm{K}^{+}\left(\mathrm{Na}^{+}\right) / \mathrm{H}^{+}$antiporters. In the chloroplast IE two $\mathrm{K}^{+} / \mathrm{H}^{+}$antiporters, KEA1 and KEA2, and $\mathrm{Na}^{+} / \mathrm{H}^{+}$antiporter NHD1 were identified (Kunz et al., 2014). These cation $/ \mathrm{H}^{+}$antiporters transport $\mathrm{H}^{+}$downhill into the stroma (hence, acidifying it), and export $\mathrm{K}^{+}$(or $\mathrm{Na}^{+}$) to the cytosol (thus, assisting the chloroplast regulated volume decrease). Consequently, triple kea1kea2nhd1 lack-of-function mutants displayed a severe phenotype, with swollen or broken chloroplasts (Kunz et al., 2014). These two different types of the IE $\mathrm{K}^{+}\left(\mathrm{Na}^{+}\right) / \mathrm{H}^{+}$antiport systems, one based on $\mathrm{K}^{+}\left(\mathrm{Na}^{+}\right) / \mathrm{H}^{+}$ antiporters and another consisting of a non-selective cation channel and of an $\mathrm{H}^{+}$pump, should be both essential for stromal $\mathrm{pH}$ control and chloroplast volume regulation, exerting the effects opposite one to another. It was shown that osmotic adjustment in chloroplasts, crucial for the photosynthesis efficiency, requires transport of organic osmolytes in addition to inorganic ions and that the permeability of the IE for sugars is increased upon acute water stress (Robinson, 1985; McCain, 1995). This argues for the activity of mechanosensitive channels, which pores are wide enough to transport sugars. As far as we know, mechanical stretch-stimulation was never tested upon in situ patch-clamp measurements on intact chloroplasts, which may be addressed for future studies. However, the presence of MscS-like MSL 2 and 3 channels in the IE and their impact on the chloroplast volume was demonstrated, suggesting that they form functional mechanosensitive channels in Arabidopsis (Haswell and Meyerowitz, 2006). Ionic selectivity of MSL 2 and 3 is unknown, whereas a related MSC1 channel in Chlamydomonas chloroplasts is selective for anions over $\mathrm{K}^{+}$(Nakayama et al., 2007). On the other hand, FACC was permeable to N-methyl Dglucamine (Pottosin et al., 2005), and, therefore, possesses a pore wide enough to transport monosaccharides.

\section{Anion Channel (PIRAC) in the Pea Envelope Membrane}

In an interesting variation with our data, direct patch-clamping of pea chloroplasts by other group revealed that the envelope conductance in their case was dominated by a voltageindependent $50 \mathrm{pS}$ anion channel (van den Wijngaard and Vredenberg, 1997, 1999; van den Wijngaard et al., 1999). Its open probability was negatively regulated by protein precursors (preferredoxin), so it was named PIRAC (for protein import related anion channel) and its interaction with the IE protein translocon (Tic) was considered, although it probably did not form a part of the Tic pore (van den Wijngaard and Vredenberg, 1999; van den Wijngaard et al., 2000). An anion channel has to be present in the IE (and possibly, also in the OE) due to the fact of a large cytosolic $\mathrm{Cl}^{-}$decrease, caused by the light-driven anion uptake by chloroplasts (Thaler et al., 1991). Because PIRAC activity was studied in a relatively narrow voltage range, $\pm 40 \mathrm{mV}$, where FACC open probability did not exceed $2 \%$, FACC could be easily overlooked. However, how could we, in turn, overlook the activity of PIRAC, which open probability was close to 1 ? Comparison of our experimental conditions with those employed by van den Wijngaard and co-workers, revealed a single potentially important difference: for some reasons these authors used $\mathrm{Mg}^{2+}$-free solutions, whereas in our case minimal free $\mathrm{Mg}^{2+}$ concentration at either membrane side was $1 \mathrm{mM}$ (Pottosin et al., 2005). It is well known that the activity of mCS anion channel of the inner mitochondrial membrane is completely abolished by inclusion of $1 \mathrm{mM} \mathrm{Mg}^{2+}$ in solutions (Borecký et al., 1997). High intracellular $\mathrm{Mg}^{2+}$ also inhibits volume-regulated anion channels (Nilius and Droogmans, 2003). This opens a very interesting perspective, as $\mathrm{Mg}^{2+}$ may act as a natural regulator of PIRAC.

\section{OUTLOOK}

In vitro studies of individual $\mathrm{OE}$ porins, either purified native or recombinant proteins, is undoubtedly a very important source of information on their detailed properties. However, it is believed, albeit not proved experimentally, that all or at least some OEPs are negatively controlled in vivo and in situ, so that they are closed most of time and open only on demand- the situation, obviously, rather different from their high open probability in vitro (Bölter and Soll, 2001; Duy et al., 2007). Direct patchclamping of the intact chloroplast envelope may be the way to prove or disprove this hypothesis. Up to the moment, only two groups, our lab and that from Prof. Vredenberg were succeeded in direct intact chloroplast patch-clamping, and most of available information for a higher plant chloroplast was obtained on a single species - the pea. The pea played an important role in OEP studies, as OEPs were first identified in this species and only afterwards in Arabidopsis. Nevertheless, there is really a 
need to extend the list of explored species. Arabidopsis and rice chloroplasts are on the top of this list. We are unaware of such attempts in the past and may not judge, whether the absence of respective information is due to an extremely low success rate or just unwillingness to try. However, as pea chloroplasts were not uniquely patch-clamp friendly, we believe that it is worth to pursue the patch-clamp trials. We are also thinking that a concurrent implementation of a non-invasive MIFE technique to study ion fluxes on chloroplasts arrays, similar to the previous application of MIFE to studies on microorganisms (Shabala et al., 2006), may be of importance to elucidate the transenvelope ion transport in situ. Our observations on electrical behavior of pea chloroplasts upon patching raised the possibility to register currents from the two envelope membranes in series. This model, of course, requires further proofs. However, a tightly regulated membrane conductance, revealed in our experiments as compared to a vast variety of poorly regulated conductance states in reconstituted studies (Mi et al., 1994; Heiber et al., 1995), appears to be more consistent with barrier properties of the IE. Thylakoid membrane patching, and, in particular, patching native thylakoid membrane of Arabidopsis, represents an interesting and potentially rewarding task for the future. Again, available data are too scarce for generalizations. Nevertheless, the dominant anion channel seems to be conserved as it was detected in only two distantly related dicotyledonous species and in alga chloroplasts. Its identity with $\mathrm{ClC}$ (ClCe?), regulation by protons, and pharmacological profile remain to be elucidated. Divalent cation-permeable channel so far

\section{REFERENCES}

Allen, G. A., Amtmann, A., and Sanders, D. (1998). Calcium-dependent and calcium-independent $\mathrm{K}^{+}$mobilization channels in Vicia faba guard cell vacuoles. J. Exp. Bot. 49, 305-318. doi: 10.1093/jxb/49.Special_ Issue. 305

Allen, J. F., and Holmes, N. G. (1986). "Electron transport and redox titration," in Photosynthesis-Energy Transduction: A Practical Approach, eds M. F. Hipkins and N. R. Baker (Oxford: IRL Press), 103-141.

Armbuster, U., Carrillo, L. R., Venema, K., Pavlovic, L., Schmidtmann, E., Kornfeld, A., et al. (2014). Ion antiport accelerates photosynthetic acclimation in fluctuating light environments. Nat. Comm. 5, 5439. doi: 10.1038/ncomms6439

Becker, D., Geiger, D., Dunkel, M., Roller, A., Bertl, A., Latz, A., et al. (2004). AtTPK4, an Arabidopsis tandem-pore K_channel, poised to control the pollen membrane voltage in a $\mathrm{pH}$ - and $\mathrm{Ca}^{2+}$-dependent manner. Proc. Natl. Acad. Sci. U.S.A. 101, 15621-15626. doi: 10.1073/pnas.0401502101

Berkowitz, G. A., and Peters, J. S. (1993). Chloroplast inner-envelope ATPase acts as a primary $\mathrm{H}^{+}$pump. Plant Physiol. 102, 261-267. doi: 10.1104/pp.102.1.261

Block, M. A., Douce, R., Joyard, J., and Rolland, N. (2007). Chloroplast envelope membranes: a dynamic interface between plastids and the cytosol. Photosyn. Res. 92, 225-244. doi: 10.1007/s11120-007-9195-8

Bölter, B., and Soll, J. (2001). Ion channels in the outer membranes of chloroplasts and mitochondria: open doors or regulated gates? EMBO J. 20, 935-940. doi: 10.1093/emboj/20.5.935

Bölter, B., Soll, J., Hill, K., Hemmler, R., and Wagner, R. (1999).A rectifying ATPregulated solute channel in the chloroplastic outer envelope from pea. $E M B O \mathrm{~J}$. 18, 5505-5516. doi: 10.1093/emboj/18.20.5505

Borecký, J., Jezek, P., and Siemen, D. (1997). 108-pS channel in brown fat mitochondria might be identical to the inner membrane anion channel. J. Biol. Chem. 272, 19282-19289. was found only in spinach thylakoid membrane (Pottosin and Schönknecht, 1996). Do similar channels exist in thylakoid membranes of other higher plant species? If so, what is their molecular identity and actual roles in stromal $\mathrm{Ca}^{2+}$ signaling and control of $\mathrm{CO}_{2}$ fixation by $\mathrm{Mg}^{2+}$ ? Finally, an interesting approach of thylakoid transport studies may be the achievement of a whole thylakoid configuration, using a perforated patch technique. It will allow not only to record currents mediated by all present ion channels, but in conjunction with it also measure light-induced electron and $\mathrm{H}^{+}$transport under strictly controlled voltage and $\mathrm{pH}$ conditions. This may represent a more direct way to study the effects of $\mathrm{pH}$ and voltage on the photosynthetic transfer and to reveal particular contributions of different ion channels into a dynamic control of the thylakoid $\Delta \Psi$.

\section{AUTHOR CONTRIBUTIONS}

IP was in charge of general planning, writing, editing, and figures design. OD performed database search, writing, editing, and proof-reading.

\section{ACKNOWLEDGMENTS}

Both authors are grateful for CONACyT for a continuous support. The authors are thankful to Mr. Scott Hayes for his indispensable help in editing the paper for English language and style.

Bräutigam, A., Hofmann-Benning, S., and Weber, A. P. M. (2008). Comparative proteomics of chloroplast envelopes from $\mathrm{C} 3$ and $\mathrm{C} 4$ plants reveals specific adaptations of the plastid envelope to $\mathrm{C} 4$ photosynthesis and candidate proteins required for maintaining C4 metabolite fluxes. Plant Physiol. 148, 568-579. doi: 10.1104/pp.108.121012

Breuers, F. H. H., Bräutigam, A., and Weber, A. P. M. (2011). The plastid outer envelope- a highly dynamic interface between plastid and cytoplasm. Front. Plant Sci. 2:97. doi: 10.3389/fpls.2011.00097

Brüggemann, L. I., Pottosin, I. I., and Schönknecht, G. (1999). Cytoplasmic magnesium regulates the fast activating vacuolar cation channel. J. Exp. Bot. 50, 1547-1552. doi: 10.1093/jxb/50.339.1547

Bulychev, A. A., Andrianov, V. K., Kurella, G. A., and Litvin, F. F. (1972), Microelectrode measurements of the ransmembrane potential of chloroplasts and its photoinduced changes. Nature 236, 175-177. doi: 10.1038/236175a 0

Bulychev, A. A., Antonov, V. F., and Schevchenko, E. V. (1992). Patch-clamp studies of light-induced currents across the thylakoid membrane of isolated chloroplasts. Biochim. Biophys. Acta Bioenerg. 1099, 16-24. doi: 10.1016/00052728(92) $90182-2$

Cakmak, I., and Kirkby, E. A. (2008). Role of magnesium in carbon partitioning and alleviating photooxidative damage. Physiol. Plant. 133, 692-704. doi: $10.1111 /$ j.1399-3054.2007.01042.x

Campo, M. L., and Tedeschi, H. (1985). Protonmotive force and photophosphorylation in single swollen thylakoid vesicles. Eur. J. Biochem. 149, 511-516. doi: 10.1111/j.1432-1033.1985.tb08954.x

Carraretto, L., Formentin, E., Teardo, E., Checchetto, V., Tomizioli, M., Morosinotto, T., et al. (2013). A thylakoid-located two-pore $\mathrm{K}^{+}$channel controls photosynthetic light utilization in plants. Science 342, 114-118. doi: $10.1126 /$ science. 1242113

Chardot, T., and Meunier, J. -C. (1991). Properties of oxidized and reduced spinach (Spinacia oleracea) chloroplast fructose-1,6-bisphosphatase activated by various agents. Biochem. J. 278, 787-781. doi: 10.1042/bj2780787 
Checchetto, V., Teardo, E., Carraretto, L., Formentin, E., Bergantino, E., Giacometti, G. M., et al. (2013). Regulation of photosynthesis by ion channels in cyanobacteria and higher plants. Biophys. Chem. 182, 51-57. doi: 10.1016/j.bpc.2013.06.006

Colombini, M. (2012a). Mitochondrial outer membrane channels. Chem. Rev. 112, 6373-6387. doi: 10.1021/cr3002033

Colombini, M. (2012b). VDAC structure, selectivity, and dynamics. Biochim. Biophys. Acta 1818, 1457-1465. doi: 10.1016/j.bbamem.2011.12.026

Colombini, M., Yeung, C. L., Tung, J., and König, T. (1987). The mitochondrial outer membrane channel, VDAC, is regulated by a synthetic polyanion. Biochim. Biophys. Acta 905, 279-286.

Cruz, J. A., Sacksteder, C., Kanazawa, A., and Kramer, D. M. (2001). Contribution of electric field $\Delta \Psi$ to steady-state transthylakoid proton motive force in vitro and in vivo. Control of pmf parsing into $\Delta \Psi$ and $\Delta \mathrm{pH}$ by counterion fluxes. Biochemistry 40, 1226-1237. doi: 10.1021/bi0018741

Demmig, B., and Gimmler, H. (1983). Properties of the isolated intact chloroplast at cytoplasmic $\mathrm{K}^{+}$concentrations.I. Light-induced cation uptake into intact chloroplasts is driven by an electrical potential difference. Plant Physiol. 73, 169-174. doi: 10.1104/pp.73.1.169

Duy, D., Soll, J., and Philippar, K. (2007). Solute channels of the outer membrane: from bacteria to chloroplasts. Biol. Chem. 388, 879-889. doi: 10.1515/BC. 2007.120

Enz, C., Steinkamp, T., and Wagner, R. (1993). Ion channels in the thylakoid membrane (A Patch Clamp Study). Biochim. Biophys. Acta 1143, 67-76. doi: 10.1016/0005-2728(93)90217-4

Ettinger, W. F., Clear, A. M., Fanning, K. J., and Peck, M. L. (1999). Identification of a $\mathrm{Ca}^{2+} / \mathrm{H}^{+}$antiport in the plant chloroplast thylakoid membrane. Plant Physiol. 119, 1379-1385. doi: 10.1104/pp.119.4.1379

Fischer, S., and Gräber, P. (1999). Comparison of $\Delta \mathrm{pH}$ - and $\Delta \Psi$-driven ATP synthesis catalyzed by the $\mathrm{H}^{+}$-ATPases from Escherichia coli or chloroplasts reconstituted into liposomes. FEBS Lett. 457, 327-332.

Flügge, U., and Benz, R. (1984). Pore forming activity in the outer membrane of the chloroplast envelope. FEBS Lett. 169, 85-89. doi: 10.1016/0014-5793(84) 80294-X

Flügge, U. I. (2000). Transport in and out of plastids: does the outer envelope membrane control the flow? Trends Plant Sci. 5, 135-137. doi: 10.1016/S13601385(00)01578-8

Gimmler, H., Schäfer, G., and Heber, U. (1974). "Low permeability of the chloroplast envelope towards cations," in Proceedings of the 3rd International Congress on Photosynthesis Research, Vol. 3, ed M. Avron (Amsterdam: Elsevier), 1381-1392.

Goetze, T. A., Patil, M., Jeshen, I., Bölter, B., Grahl, S., and Soll, J. (2015). Oep23 forms an ion channel in the chloroplast outer enveliope. BMC Plant Biol. 15:47. doi: 10.1186/s12870-015-0445-1

Goetze, T. A., Philippar, K., Ilkavets, I., Soll, J., and Wagner, R. (2006). OEP37 is a new member of the chloroplast outer membrane ion channels. J. Biol. Chem. 281, 17989-17998. doi: 10.1074/jbc.M600700200

Gould, S. B., Waller, R. F., and McFadden, G. I. (2008). Plastid evolution. Annu. Rev. Plant Biol. 59, 491-517. doi: 10.1146/annurev.arplant.59.032607. 092915

Gutierrez-Carbonell, E., Takahashi, D., Lattanzio, G., Rodríguez-Celma, J., Kehr, J., Soll, J., et al. (2014). The distinct functional roles of the inner and outer chloroplast envelope of pea (Pisum sativum) as revealed by proteomic approaches. J. Proteome Res. 13, 2941-2953. doi: 10.1021/pr500106s

Hamill, O. P., Marty, A., Neher, E., Sakmann, B., and Sigworth, F. J. (1981). Improved patch clamp technique for high-resolution current recording from cells and cell free patches. Pfluegers Arch. 391, 85-100. doi: 10.1007/BF006 56997

Haswell, E. S., and Meyerowitz, E. M. (2006). MscS-like proteins control plastid size and shape in Arabidopsis thaliana. Curr. Biol. 16, 1-11. doi: 10.1016/j.cub.2005.11.044

Heiber, T., Steinkamp, T., Hinnah, S., Schwarz, M., Flügge, U. I., Weber, A., et al. (1995). Ion channels in the chloroplast envelope membrane. Biochemistry 34, 15906-15917. doi: 10.1021/bi00049a005

Heldt, H. W., Werdan, K., Milovancev, M., and Geller, G. (1973). Alkalinization of the chloroplast stroma caused by light-dependent proton flux into the thylakoid lumen. Biochim. Biophys. Acta 314, 224-241. doi: 10.1016/00052728(73)90137-0
Hemmler, R., Becker, T., Schleiff, E., Bölter, B., Stahl, T., Soll, J., et al. (2006). Molecular properties of Oep21, an ATP-regulated anion- selective solute channel from the outer chloroplast membrane. J. Biol. Chem. 281, 12020-12029. doi: 10.1074/jbc.M513586200

Herick, K., Krämer, R., and Lúhring, H. (1997). Patch clamp investigation into the phosphate carrier from Saccharomyces cerevisiae mitochondria. Biochim. Biophys. Acta 1321, 207-220. doi: 10.1016/S0005-2728(97)00050-9

Hertig, C., and Wolosiuk, R. A. (1980). A dual effect of $\mathrm{Ca}^{2+}$ on chloroplast fructose-1,6-bisphosphatase. Biochem. Biophys. Res. Commun. 97, 325-333. doi: 10.1016/S0006-291X(80)80171-9

Hind, G., Nakatani, H. Y., and Izawa, S. (1974). Light-dependent redistribution of ions in suspensions of chloroplast thylakoid membranes. Proc. Natl. Acad. Sci. U.S.A. 71, 1484-1488. doi: 10.1073/pnas.71.4.1484

Hinnah, S., and Wagner, R. (1998). Thylakoid membranes contain a highconductance channel. Eur. Biochem. J. 253, 606-613. doi: 10.1046/j.14321327.1998.2530606.x

Inoue, K. (2007). The chloroplast outer envelope membrane: the edge of light and excitement. J. Integrat. Plant Biol. 49, 1100-1111. doi: 10.1111/j.16729072.2007.00543.x

Ishijima, S., Uchibori, A., Takagi, H., Maki, R., and Ohnishi, M. (2003). Light-induced increase in free $\mathrm{Mg}^{2+}$ concentration in spinach chloroplasts: measurement of free $\mathrm{Mg}^{2+}$ by using a fluorescent probe and necessity of stromal alkalinization. Arch. Biochem. Biophys. 412, 126-132. doi: 10.1016/S0003-9861(03)00038-9

Johnson, C. H., Knight, M. R., Kondo, T., Masson, P., Sedbrook, J., Haley, A., et al. (1995). Circadian oscillations of cytosolic and chloroplastic free calcium in plants. Science 269, 1863-1865. doi: 10.1126/science.7569925

Kirchhoff, H. (2008). Molecular crowding and order in photosynthetic membranes. Trends Plant Sci. 13, 201-207. doi: 10.1016/j.tplants.2008.03.001

Kirchhoff, H., Mukherjee, U., and Galla, H. -J. (2002). Molecular architecture of the thylakoid membrane: lipid diffusion space for plastoquinone. Biochemistry 41, 4872-4882. doi: 10.1021/bi011650y

Klughammer, C., Siebke, K., and Schreiber, U. (2013). Continuous ECS-indicated recording of the proton-motive charge flux in leaves. Photosynth. Res. 117, 471-487. doi: 10.1007/s11120-013-9884-4

Kramer, D. M., Avenson, T. J., and Edwards, G. E. (2004). Dynamic flexibility in the light reactions of photosynthesis governed by both electron and proton transfer reactions. Trends Plant Sci. 9, 349-357. doi: 10.1016/j.tplants.2004.05.001

Kramer, D. M., Cruz, J. A., and Kanazawa, A. (2003). Balancing the central roles of the thylakoid proton gradient. Trends Plant Sci. 8, 27-32. doi: 10.1016/S13601385(02)00010-9

Kunz, H. H., Gierth, M., Herdean, A., Satoh-Cruz, M., Kramer, D. M., Spetea, C., et al. (2014). Plastidial transporters KEA1, -2, and -3 are essential for chloroplast osmoregulation, integrity, and $\mathrm{pH}$ regulation in Arabidopsis. Proc. Natl. Acad. Sci. U.S.A. 111, 7480-7485. doi: 10.1073/pnas.1323899111

Labarca, P., and Latorre, R. (1992). "Insertion of ion channels into planar lipid bilayers by vesicle fusion," in Methods in Enzymology: Vol. 207, Ion Channels, eds B. Rudy and L. E. Iverson (New York, NY: Academic Press), 447-463.

Li, L., Yan, J., and Tang, Z. (1996). Direct measurement of the $\mathrm{K}^{+}$-channel and its ion selectivity in the thylakoid membrane from spinach (Spinacea oleracea L.) leaves. Acta Bot. Sin. 38, 692-698.

Marmagne, A., Vinauger-Doyard, M., Monachello, D., Falcon de Longevialle, A., Charon, C., Allot, M., et al. (2007). Two members of the Arabidopsis CLC (chloride channel) family, AtCLCe and AtCLCf, are associated with thylakoid and Golgi membranes, respectively. J. Exp. Bot. 58, 3385-3393. doi: $10.1093 / \mathrm{jxb} / \mathrm{erm} 187$

Maury, W. J., Huber, S. C., and Moreland, D. E. (1981). Effects of magnesium on intact chloroplasts. II. Cation specificity and involvement of the envelope ATPase in (sodium) potassium/proton exchange across the envelope. Plant Physiol. 68, 1257-1263. doi: 10.1104/pp.68.6.1257

McCain, D. C. (1995). Combined effects of light and water stress on chloroplast volume regulation. Biophys. J. 69, 1105-1110. doi: 10.1016/S00063495(95)79984-2

Mi, F., Berkowitz, G. A., and Peters, J. S. (1994). Characterization of a chloroplast inner envelope $\mathrm{K}^{+}$channel. Plant Physiol. 105, 955-964. doi: 10.1104/pp.105.3.955

Miller, C. (2006). ClC chloride channels viewed through a transport lens. Nature 220, 484-489. doi: 10.1038/nature04713 
Mitchell, P. (1966). Chemiosmotic coupling in oxidative and photosynthetic phosphorylation. Biol. Rev. Cambridge Phil. Soc. 41, 445-502. doi: 10.1111/j.1469-185X.1966.tb01501.x

Monachello, D., Allot, M., Oliva, S., Krapp, A., Daniel-Videle, F., BarbierBrygoo, H., et al. (2009). Two anion transporters AtClCa and AtClCe fulfill interconnecting but not redundant roles in nitrate assimilation pathways. New Phytol. 183, 88-94. doi: 10.1111/j.1469-8137.2009. 02837.x

Muñiz, J. M., Pottosin, I. I., and Sandoval, L. (1995). Patch-clamp study of vascular plant chloroplasts: ion channels and photocurrents. J. Bioenerg. Biomembr. 27, 249-258. doi: 10.1007/BF02110040

Muto, S., Izawa, S., and Miyachi, S. (1982). Light-induced $\mathrm{Ca}^{2+}$ uptake by intact chloroplasts. FEBS Lett. 139, 250-254. doi: 10.1016/0014-5793(82) 80863-6

Nakayama, Y., Fujiu, K., Sokabe, M., and Yoshimura, K. (2007). Molecular and electrophysiological characterization of a mechanosensitive channel expressed in the chloroplasts of Chlamydomonas. Proc. Natl. Acad. Sci. U.S.A. 104, 5883-5888. doi: 10.1073/pnas.0609996104

Nilius, B., and Droogmans, G. (2003). Amazing chloride channels: an overview. Acta Physiol. Scand. 177, 119-147. doi: 10.1046/j.1365-201X.2003. 01060.x

Nomura, H., Komori, T., Uemura, S., Kanda, Y., Shimotani, K., Nakai, K., et al. (2012). Chloroplast-mediated activation of plant immune signalling in Arabidopsis. Nat. Commun. 3, 926. doi: 10.1038/ncomms1926

Nomura, H., and Shiina, T. (2014). Calcium signaling in plant endosybiotic organelles: mechanism and role in physiology. Mol. Plant 7, 1094-1104. doi: $10.1093 / \mathrm{mp} / \mathrm{ssu} 020$

Pelzer, D. J., McDonald, T. F., and Pelzer, S. (1993). "Reconstitution of muscle calcium channel function in bilayer membranes: from the first steps to results," in Methods in Pharmacology: Vol. 7, Molecular and Cellular Biology of Pharmacological Targets, eds H. Glossmann and J. Striessnig (New York, NY: Springer Sci.), 99-140.

Pfeil, B. E., Schoefs, B., and Spetea, C. (2014). Function and evolution of channels and transporters in photosynthetic membranes. Cell. Mol. Life Sci. 71, 979-998. doi: 10.1007/s00018-013-1412-3

Pohlmeyer, K., Soll, J., Grimm, R., Hill, K., and Wagner, R. (1998). A highconductance solute channel in the chloroplastic outer envelope from pea. Plant Cell 10, 1207-1216. doi: 10.1105/tpc.10.7.1207

Pohlmeyer, K., Soll, J., Steinkamp, T., Hinnah, S., and Wagner, R. (1997). Isolation and characterization of an amino acid-selective channel protein present in the chloroplastic outer envelope membrane. Proc. Natl. Acad. Sci. U.S.A. 94, 9504-9509. doi: 10.1073/pnas.94.17.9504

Porcelli, A. M., Ghelli, A., Zanna, C., Pinto, P., Rizzuto, R., and Rugolo, M. (2005). $\mathrm{pH}$ difference across the outer mitochondrial membrane measured with a green fluorescent protein mutant. Biochem. Biophys. Res. Commun. 326, 799-804. doi: 10.1016/j.bbrc.2004.11.105

Portis, A., and Heldt, H. W. (1976). Light dependent changes of the $\mathrm{Mg}^{2+}$ concentration in the stroma in relation to the $\mathrm{Mg}^{2+}$ dependency of $\mathrm{CO}_{2}$ fixation in intact chloroplasts. Biochim. Biophys. Acta 449, 434-446. doi: 10.1016/0005-2728(76)90154-7

Portis, A. R. (1981). Evidence of a low stromal $\mathrm{Mg}^{2+}$ concentration in intact chloroplasts in the dark I. Studies with the ionophore A23187. Plant Physiol. 67, 985-989. doi: 10.1104/pp.67.5.985

Portis, A. R., Chon, C. J., Mosbach, A., and Heldt, H. W. (1977). Fructose- and sedoheptulose-bisphosphatase. The site of a possible control of $\mathrm{CO}_{2}$ fixation by light-dependent changes of the stromal $\mathrm{Mg}^{2+}$ concentration. Biochim. Biophys. Acta 461, 313-325. doi: 10.1016/0005-2728(77)90181-5

Pottosin, I. I. (1992). Single channel recording in the chloroplast envelope. FEBS Lett. 308, 87-90. doi: 10.1016/0014-5793(92)81057-S

Pottosin, I. I. (1993). One of the chloroplast envelope ion channels is probably related to the mitochondrial VDAC. FEBS Lett. 330, 211-214. doi: 10.1016/0014-5793(93)80275-Y

Pottosin, I. I., Muñiz, J., and Shabala, S. (2005). Fast-activating channel controls cation fluxes across the native chloroplast envelope. J. Membr. Biol. 204, 145-156. doi: 10.1007/s00232-005-0758-3

Pottosin, I. I., and Schönknecht, G. (1995a). Patch clamp study of the voltagedependent anion channel in the thylakoid membrane. J. Membr. Biol. 148, 143-156. doi: 10.1007/BF00207270
Pottosin, I. I., and Schönknecht, G. (1995b). "Anion and cation channels in the thylakoid membrane," in Photosynthesis: from Light to Biosphere, Vol. 3, ed P. Mathis (Dorderecht: Kluwer Acad. Publ.), 99-102.

Pottosin, I. I., and Schönknecht, G. (1996). Ion channel permeable for divalent and monovalent cations in native spinach thylakoid membranes. J. Membr. Biol. 152, 223-233. doi: 10.1007/s002329900100

Pottosin, I., and Shabala, S. (2015). Transport across chloroplast membranes: optimizing photosynthesis for adverse environmental conditions. Mol. Plant. doi: 10.1016/ j.molp.2015.10.006. [Epub ahead of print].

Pribil, M., Labs, M., and Leister, D. (2014). Structure and dynamics of thylakoids in land plants. J. Exp. Bot. 65, 1955-1972. doi: 10.1093/jxb/eru090

Pudelski, B., Kraus, S., Soll, J., and Phillipar, K. (2010). The plant PRAT proteinspreprotein and amino acid transport in mitochondria and chloroplasts. Plant Biol. 12, 42-55. doi: 10.1111/j.1438-8677.2010.00357.x

Pudelski, B., Schock, A., Hoth, S., Radchuk, R., Weber, H., Hofmann, J., et al. (2012). The plastid outer envelope protein OEP16 affects metabolic fluxes during ABA-controlled seed development and germination. J. Exp. Bot. 63, 1919-1936. doi: 10.1093/jxb/err375

Remiš, D., Bulychev, A. A., and Kurella, G. A. (1986). The electrical and chemical components of the protonmotive force in chloroplasts as measured with capillary and pH-sensitive microelecrodes. Biochim. Biophys. Acta 852, 68-73. doi: 10.1016/0005-2728(86)90057-5

Robinson, S. P. (1985). Osmotic adjustment by intact isolated chloroplasts in response to osmotic stress and its effect on photosynthesis and chloroplast volume. Plant Physiol. 79, 996-1002. doi: 10.1104/pp.79.4.996

Röhl, T., Motzkus, M., and Soll, J. R. (1999). The outer envelope protein OEP24 from pea chloroplasts can functionally replace the mitochondrial VDAC in yeast. FEBS Lett. 460, 491-494. doi: 10.1016/S0014-5793(99)01399-X

Roh, M. H., Shingles, R., Cleveland, M. J., and McCarty, R. (1998). Direct measurement of calcium transport across chloroplast inner-envelope vesicles. Plant Physiol. 118, 1447-1454. doi: 10.1104/pp.118.4.1447

Rolland, N., Gurie, G., Finazzi, J., Kuntz, M., Maréchal, E., Marringe, M., et al. (2012). The biosynthetic capacities of the plastids and integration between cytoplasmic and chloroplast processes. Annu. Rev. Genet. 46, 233-264. doi: 10.1146/annurev-genet-110410-132544

Schindl, R., and Weghuber, J. (2012). "Electrophysiological techniques for mitochondrial channels, patch clamp technique," ed F. S. Kaneez (InTech), 163-169. Available online at: http://www.intechopen.com/books/patch-clamptechnique/electrophysiological-techniques-for-mitochondrialchannels

Schönknecht, G., Althoff, G., and Junge, W. (1990). The electric unit size of thylakoid membranes. FEBS Lett. 277, 65-68. doi: 10.1016/00145793(90)80810-6

Schönknecht, G., Hedrich, R., Junge, W., and Raschke, K. (1988). A voltagedependent chloride channel in the photosynthetic membrane of a higher plant. Nature 336, 589-592.

Schönknecht, G., Neimanis, S., Katona, E., Gerst, U., and Heber, U. (1995). Relationship between photosynthetic electron transport and $\mathrm{pH}$ gradient across the thylakoid membrane in intact leaves. Proc. Natl. Acad. Sci. U.S.A. 92, 12185-12189. doi: 10.1073/pnas.92.26.12185

Schwarz, M., Gross, A., Steinkamp, T., Flügge, U. I., and Wagner, R. (1994). Ion channel properties of the reconstituted chloroplast triose phosphate/ phosphate translocator. J. Biol. Chem. 269, 29481-29489.

Shabala, L., Ross, T., McMeekin, T., and Shabala, S. (2006). Non-invasive microelectrode ion flux measurements to study adaptive responses of microorganisms to the environment. FEMS Microbiol. Rev. 30, 472-486. doi: 10.1111/j.1574-6976.2006.00019.x

Shimoni, E., Rav-Hon, O., Ohad, I., Brumfeld, V., and Reich, Z. (2005). Three-dimensional organization of higher-plant chloroplast thylakoid membranes revealed by electron tomography. Plant Cell 17, 2580-2586. doi: $10.1105 /$ tpc.105.035030

Soll, J., Bölter, B., Wagner, R., and Hinnah, S. C. (2000). ...response: the chloroplast outer envelope: a molecular sieve? Trends Plant Sci. 5, 137-138. doi: 10.1016/S1360-1385(00)01579-X

Sorgato, M. C., Keller, B. U., and Stühmer, W. (1987). Patch-clamping of the inner mitochondrial membrane reveals a voltage-dependent ion channel. Nature 330, 498-500. doi: $10.1038 / 330498 \mathrm{a} 0$

Steinkamp, T., Hill, K., Hinnah, S. C., Wagner, R., Röhl, T., Pohlmeyer, $\mathrm{K}$., et al. (2000). Identification of the pore-forming region of the outer 
chloroplast envelope protein OEP16. J. Biol. Chem. 275, 11758-11764. doi: $10.1074 /$ jbc.275.16.11758

Suchyna, T. M., Markin, V. S., and Sachs, F. (2009). Biophysics and structure of the patch and gigaseal. Biophys. J. 97, 738-747. doi: 10.1016/j.bpj.2009.05.018

Szabo, I., and Zoratti, M. (2014). Mitochondrial channels: ion fluxes and more. Physiol. Rev. 94, 519-608. doi: 10.1152/physrev.00021.2013

Takizawa, K., Cruz, J. A., Kanazawa, A., and Kramer, D. M. (2007). The thylakoid proton motive force in vivo. Quantitative, non-invasive probes, energetics, and regulatory consequences of light-induced pmf. Biochim. Biophys. Acta 1767, 1233-1244. doi: 10.1016/j.bbabio.2007.07.006

Teardo, E., Frare, E., Segalla, A., De Marco, V., Giacometti, G. M., and Szabó, I. (2005). Localization of a putative $\mathrm{ClC}$ channel in spinach chloroplasts. FEBS Lett. 579, 4991-4996. doi: 10.1016/j.febslet.2005.08.005

Teardo, E., Segalla, A., Formentin, E., Zanetti, M., Marin, O., Giacometti, G. M., et al. (2010). Characterization of a plant glutamate receptor activity. Cell. Physiol. Biochem. 26, 253-262. doi: 10.1159/000320525

Tester, M., and Blatt, M. R. (1989). Direct measurement of $\mathrm{K}^{+}$channels in thylakoid membranes by incorporation of vesicles into planar lipid bilayers. Plant Physiol. 91, 249-252. doi: 10.1104/pp.91.1.249

Thaler, M., Simonis, W., and Schönknecht, G. (1991). Light-dependent changes of the cytoplasmic $\mathrm{H}^{+}$and $\mathrm{Cl}^{-}$activity in the green alga Eremosphaera viridis. Plant Physiol. 99, 103-110. doi: 10.1104/pp.99.1.103

Tikhonov, A. N., Khomutov, G. B., Ruuge, E. K., and Blumenfeld, L. A. (1981). Electron transport in chloroplasts effects of photosynthetic control monitored by the intrathylakoid pH. Biochim. Biophys. Acta 637, 321-333. doi: 10.1016/0005-2728(81)90171-7

Tikhonova, L. I., Pottosin, I. I., Dietz, K. J., and Schönknecht, G. (1997). Fastactivating cation channel in barley mesophyll vacuoles. Inhibition by calcium. Plant J. 11, 1059-1070. doi: 10.1046/j.1365-313X.1997.11051059.x

Tomaskova, Z., and Ondrias, K. (2010). Mitochondrial chloride channels-What are they for? FEBS Lett. 584, 2085-2092. doi: 10.1016/j.febslet.2010.01.035

Ursell, T., Agrawal, A., and Phillips, B. (2011). Lipid bilayer mechanics in a pipette with glass-bilayer adhesion. Biophys. J. 101, 1913-1920. doi: 10.1016/j.bpj.2011.08.057

van den Wijngaard, P. W. J., Dabney-Smith, C., Bruce, B. D., and Vredenberg, W. J. (1999). The mechanism of inactivation of a 50-pS envelope anion channel during chloroplast protein import. Biophys. J. 77, 3156-3162. doi: 10.1016/S0006-3495(99)77146-8

van den Wijngaard, P. W. J., Demmers, J. A. A., Thompson, S. J., Wienk, H. L. J., de Kruiff, B., and Vredenberg, W. J. (2000). Further analysis of the involvement of the envelope anion channel PIRAC in chloroplast protein import. Eur. J. Biochem. 267, 3812-3817. doi: 10.1046/j.1432-1327.2000.01419.x

van den Wijngaard, P. W. J., and Vredenberg, W. J. (1997). A 50-picosiemens anion channel of the chloroplast envelope is involved in chloroplast protein import. J. Biol. Chem. 272, 29430-29433. doi: 10.1074/jbc.272.47.29430 van den Wijngaard, P. W. J., and Vredenberg, W. J. (1999). The envelope anion channel involved in chloroplast protein import is associated with Tic110. J. Biol. Chem. 274, 25201-22520. doi: 10.1074/jbc.274.36.25201

van Meer, G., Voelker, D. R., and Feigenson, G. W. (2008). Membrane lipids: where they are and how they behave. Nat. Rev. Mol. Cell Biol. 9, 112-124. doi: $10.1038 / \mathrm{nrm} 2330$

Viérick, A., Rolland, N., Joyard, J., Ruysschaert, J.-M., and Homblé, F. (2003). Regulation of the anion channel of the chloroplast envelope from spinach. J. Bioenerg. Biomembr. 35, 221-229. doi: 10.1023/A:1024607630952

Weber, A. P. M., and Linka, N. (2011). Connecting the plastid: transporters of the plastid envelope and their role in linking plastidial with cytosolic metabolism. Annu. Rev. Plant Biol. 62, 53-77. doi: 10.1146/annurev-arplant-042110-103903

Werdan, K., Heldt, H. W., and Milovancev, M. (1975). The role of $\mathrm{pH}$ in the regulation of carbon fixation in the chloroplast stroma. Studies on $\mathrm{CO}_{2}$ fixation in the light and dark. Biochim. Biophys. Acta. 396, 276-292. doi: 10.1016/00052728(75) $90041-9$

Wolosiuk, R. A., Hertig, C. M., Nishizawa, A. N., and Buchanan, B. B. (1982). Enzyme regulation in C-4 photosynthesis. 3. Role of $\mathrm{Ca}^{2+}$ in thioredoxinlinked activation of sedoheptulose bisphosphatase from corn leaves. FEBS Lett. 140, 31-35. doi: 10.1016/0014-5793(82)80514-0

Wu, W., and Berkowitz, G. A. (1992). Stromal pH and photosynthesis are affected by electroneutral $\mathrm{K}^{+}$and $\mathrm{H}^{+}$exchange through chloroplast envelope ion channels. Plant Physiol. 98, 666-672. doi: 10.1104/pp.98.2.666

Wu, W., Peters, J. S., and Berkowitz, G. A. (1991). Surface-charge mediated effects of $\mathrm{Mg}^{2}+$ on $\mathrm{K}^{+}$flux across the chloroplast envelope are associated with regulation of stromal $\mathrm{pH}$ and photosynthesis. Plant Physiol. 97, 580-587. doi: 10.1104/pp.97.2.580

Zifarelli, G., and Pusch, M. (2010a). CLC transport proteins in plants. FEBS Lett. 584, 2122-2127. doi: 10.1016/j.febslet.2009.12.042

Zifarelli, G., and Pusch, M. (2010b). The role of protons in fast and slow gating of the Torpedo chloride channel ClC-0. Eur. Biophys. J. 39, 869-875. doi: 10.1007/s00249-008-0393-x

Zifarelli, G., and Pusch, M. (2012). A kick-start for CLC antiporters' pharmacology. Chem. Biol. 19, 1358-1359. doi: 10.1016/j.chembiol.2012.10.009

Conflict of Interest Statement: The authors declare that the research was conducted in the absence of any commercial or financial relationships that could be construed as a potential conflict of interest.

Copyright () 2015 Pottosin and Dobrovinskaya. This is an open-access article distributed under the terms of the Creative Commons Attribution License (CC BY). The use, distribution or reproduction in other forums is permitted, provided the original author(s) or licensor are credited and that the original publication in this journal is cited, in accordance with accepted academic practice. No use, distribution or reproduction is permitted which does not comply with these terms. 